\title{
IAMJ
}

INTERNATIONAL

AYURVEDIC

MEDICAL JOURNAL

\section{TRANSFORMATION NEEDS IN AYURVEDA EDUCATION: WHERE \& HOW}

\author{
Nitesh Gupta ${ }^{1}$, Rashmi Tiwari ${ }^{2}$ \\ ${ }^{1}$ Reader, Department of Kriya Sharir, Govt. Ayurved College, Junagadh, Gujarat, India \\ ${ }^{2}$ Reader, Department of Agadtantra, Govt. Ayurved College, Junagadh, Gujarat, India
}

Corresponding Author: drniteshgupta02@gmail.com

https://doi.org/10.46607/iamj2908102020

(Published online: October 2020)

Open Access

(C) International Ayurvedic Medical Journal, India 2020

Article Received: 14/08/2020 - Peer Reviewed: 11/09/2020 - Accepted for Publication: 11/09/2020

Check for updates

\begin{abstract}
The students with different backgrounds having habituated to different type of teaching methods and terminologies are joining Ayurveda education and there is big mismatch between their expectation, perception and actual teaching and training. Teaching and learning process in Ayurveda colleges has not much changed in spite of availability of technological tools. There will be need of dynamic continuum between research, education and practice. Better teaching techniques and modernization of Ayurveda education will improve the clinical and academic output, which in turn make them able to be presentable for ayurvedic principles. So, in order to convert Ayurveda to global level from the traditional way, it is necessary to adopt the latest technological tools and scientific framework in Ayurveda education. There will be urgent need to update and modernize the education system of Ayurveda and make the curriculum which is student centric and teacher should be facilitator. A multi-disciplinary approach in education system will be better for Indian system of medicine where some teachers from pharmaceutical chemistry, analytical chemistry, botany, phyto chemistry etc. will be appointed in institutions to provide the required trainings. Quality of institutions are very important concern in Ayurveda education sector. Quality of teachers also play very important role in providing quality education to students because only through good education a relatively permanent change in personality of individuals is achieved in cognitive, psychomotor and affective domains. There is need to involve many other modern research methods in Ayurveda such as PIP and EIS. Medical informatics, Cyber medicine, Computerized Ayurveda studies will be brought revolutionary changes in the background of Ayurveda professionals.
\end{abstract}


Keywords: Education, Technology, Teaching, Modernization

\section{INTRODUCTION}

Ayurvedic education system has evolved from traditional Gurukul Paddhati to formal institutional training. In this journey our education system has honored suggestions given by different committees, councils, organizations time to time and has emerged with the current curriculum, examination pattern, entrance procedure etc. Inspite of these changes more and more ayurvedic graduates are opting for allopathic practice or joining paraclinical courses like MBA, MHA etc, where their knowledge of ayurved is hardly utilized. The answer lies in fact that current system is not sufficient enough to produce competent ayurvedic physicians. The exiting teaching methodology for ayurved fails to produce the fellows who will fulfill all the criteria of "Vaidya" by our ancient samhita. In this globalization era we are not able to stand as successful brands although we have world's best science ayurveda with us as a tool. When we think about globalization of ayurved the first question arises in our thought is, are we preparing for global pressure and exposure? The first need for this exposure is having knowledgeable and up to date scholars of Ayurved. Better teaching techniques and modernization of ayurveda education will improve the clinical and academic output, which in turn make them able to be presentable for ayurvedic principles. Better education system is the only way by which relatively permanent change in personality of individual is achieved in his cognitive, psychomotor and affective domains. When it comes to the question of doctoral and post doctoral level, what is required is to produce very high-quality research persons having cutting edge technology. Here the word technology is connoted to carry the advancing as well as thrust areas in ayurvedic medical practices. Admittedly science or theory part in ayurved can be considered as valid and futuristic in its own terms, technology part and application levels can be further refined, modified and perfect to suit the mass global demand.

\section{Need of Modernization in Ayurveda Education}

Insight about Ayurveda in India and abroad have undergone a vast change during the last two decades. A large population from all over world is being fascinated towards Ayurveda because of terms like holistic, natural, spiritual that are accompanying with it. In the context of globalization, one has to take into account the fact that Ayurveda is not only a treatment, but it is a full system of medicine and lifestyle also. As Global demand for Ayurveda has increased many folds which has created a strange situation for Ayurveda sector and particularly its education aspects all over the world. In India also, interest in Ayurveda is increasing due to various reasons but in India Ayurveda is still second option of the public. There is general feeling that present generation of Ayurvedic graduates are not well versed in Ayurvedic fundamental principle and practices. Same time, students studying in UG and PG courses of Ayurveda feel frusted and neglected due to present curriculum of Ayurveda and inefficiency of teachers. The greatest difficulty in its globalization is the lack of competent scholars with required communication skills, which may help in propagating the knowledge of Ayurveda as a science and system. So, there is urgent need to modernize education of these system to withstand the challenges of the time. Many scientists and Ayurvedic researches have adopted the principle of modern diagnosis and Ayurvedic treatment which led to the reluctance for the proper understanding of Ayurvedic fundamental principles. Modern scientific institutions like ICMR, CSIR and CDRI have worked extensively on herbal medicine from various angles and tried to provide scientific basis for the pharmacological activity of herbs. The modern pharmaceuticals which have patented various Ayurvedic products from herbal origin trying to promote herbalism to get their product accepted internationally. But Scientists are unable to understand the problem that only herbs are not Ayurveda. When these drugs are used with certain fundamental principles then only its Ayurveda practice. Therefore, to create separate identity of Ayurvedic practitioner from herbal medicine, it is essential to modernize the education system of Ayurveda with an aim to produce 
a Ayurvedic practitioner who have faith and understanding in Ayurvedic fundamental principles with appropriate knowledge of modern medical fundamentals. So, in order to convert Ayurveda to global level from the traditional way, it is necessary to adopt the latest technological tools and scientific framework in Ayurveda education.

\section{Regions Where Modernization in Ayurved Educa- tion Needed}

The present education system in Ayurveda neither deals with the problems of present-day society nor understand the problems of present-day students regarding their learning ability and understanding. This is the reason why present Ayurvedic graduates find them in a quandary where they are not able to practice Ayurveda properly. At the same time due to insufficiency of the present day Ayurvedic teachers, students are adopting for a practice which is not as per Ayurvedic fundamental principles. Therefore, there will be urgent need to update and modernize the education system of Ayurveda and make the curriculum which is student centric and teacher should be facilitator. The major problems in Ayurveda education where immediate attention are required Lack of integrated approach policy model where all streams are integrated at all levels of medical education and practice., Lack of innovation in preparation of curriculum., Lack of required exposure to basic clinical skills during graduate level of education., Non availability of standard resource material that addresses current healthcare needs of the society., Inadequate training in research domain., Too much dependence on textual references rather than practical utility., Lack of effective teaching and learning techniques., Examination and assessment based on recall memory rather than evaluating higher level thinking skills., Lack of superspeciality courses and interdisciplinary research.

\section{How Ayurveda Education System Can Be Modern- ized}

Presently India follows the policy model of parallel approach where Indian system of medicine and modern medicine are isolated within the nationwide health system. Because of this many problem like legal conflicts on cross prescription, generation of crossbreed curricu- lum, production of second-rate graduates who are neither acceptable to Indian system of medicine nor to modern medicine. Therefore, there is need to modernize the policy model with the adaption of integrated approach. In integrated approach all streams of medicine are integrated at all the levels of medical education and practice so that there will be exchange of knowledge and harmony in values. The students of Indian system of medicine get opportunity to learn mainstream science program like microbiology, pharmacognosy, clinical research, hospital management, telemedicine, medical informatics etc. Due to this approach, not only students will have more options to evolve their careers, but also, they will be able to carry out quality research in Indian system of medicine. To achieve this there is need to prepare curriculum with innovations. The following important points should be kept in consideration while updating the curriculum, Redundancy of the curriculum to be shelled off i.e. reducing some impractical, textbook oriented and literature-oriented points from curriculum. Integration of the remainder curriculum to be worked up i.e. Some essentials topic like quality assurance, coast effective medical practices, quantitative and qualitative analysis of chemical components of Ayurvedic preparations, up to date knowledge of pharmacodynamics, pharmocognistic, Phytochemical attributes of ayurvedic herbs, methods of evaluation of their pharmacological effects, advance method of drug standardization, practice management, patenting procedures, intellectual property rights and international laws etc. is required to be included. Disintegration to be transferred into problem-based learning. Problem based learning to be converted into competency-based learning. Competency based learning to be manifested through task-based learning. A multi-disciplinary approach in education system will be better for Indian system of medicine where some teachers from pharmaceutical chemistry, analytical chemistry, botany, phyto chemistry etc. will be appointed in institutions to provide the required trainings. An ideal curriculum should be based on three important factors 1) Time 2) Relevancy 3) Purpose. A curriculum has to be timely i.e. it should meet the contemporary as well as long term re- 
quirements to be foreseen. It has to be relevant i.e. relevant to all stakeholders including teachers, students and society. It has to be purposive I.e. should cater to learning objectives efficiently.

Quality of institutions are very important concern in Ayurveda education sector. Plenty of Ayurveda College are opened in few past decades which are substandard and run only for-profit making business. Many of Ayurveda institution including government institutions also lacking basic infrastructural facilities like good hospital facilities, well equipped laboratories, well equipped pharmacy, good herbal garden, good library with standard resource materials and e contents. Ministry of AYUSH and CCIM proposed several MSR and MSE but implementation of these regulations is poor. Therefore, regulating bodies have to be very strict in implementation of such regulations for the sake of improving quality of educations in Ayurveda institutions. Corruption in governing bodies and loopholes in the existing regulations should be eradicated.

Quality of teachers also play very important role in providing quality education to students because only through good education a relatively permanent change in personality of individuals is achieved in cognitive, psychomotor and affective domains. Cognitive domain targets brain and intelligence, psychomotor domain is related with skills and largely depends upon practical talents, third and most important affective domain aims the development of heart in terms of values and ethics. Therefore, there is need to formulate uniform standard policies for recruitment of teachers and only those teachers having an inclination and aptitude for teaching should enter in teaching profession. Interviews for recruitment of teaching faculties should be made transparent without any bias and mainly focus on teaching and communication skills. Academic dishonesty in any form such as on paper teachers, examination frauds, mass copying should not be tolerated. To improve the qualities of teachers there will be needed to organize more and more training programs which gives more emphasis on effective teaching methods, use of e contents, writing research papers, development of standard research protocols etc. There is need to involve experts from other fields also to improve quality of teachers for such type of trainings. There is need to involve many other modern research methods in Ayurveda such as PIP (Polycontrast Intervene Photography) and EIS (Electro interstitial scans). These types of methods can enlighten the many Ayurveda theories like Panchamahabhuta theory, Tridosha theory. These techniques show minute changes in aura, chakras related organs, circulation disturbance, sedentary habits, deadly changes etc. There should be involvement of Medical informatics, Cyber medicine, Computerized Ayurveda studies in Ayurveda education which enhances the application of computer in medical care. Medical informatics is defined as the study, invention, and implementation of structures and algorithm to improve communication, understanding and management of medical information. Cyber medicine is the internet driven practice of medicine where patients communicate with the physician through online portals. The basic knowledge should be provided to every scholars of Ayurveda. Computerized Ayurveda studies will be brought revolutionary changes in the background of Ayurveda professionals. It enhances knowledge of information science, biotechnology, computer hardware and software etc. Every scholar should update themselves with various computer-based software's such as Body Tune, Prakes, Pilex, Madhava, Rasex Etc. There is also needed to implement inquiry-based learning teaching methodology in Ayurveda. It is a dynamic modern teaching methodology which describe a range of philosophical, curricular and pedagogical approaches to teaching. It is based on john Dewy's philosophy that education begins with curiosity of learner or students. Inquiry is a form of self-directed learning, the teacher job in an inquiry-based learning environment is therefore not to provide knowledge, but instead help student along the process of discovering knowledge themselves. By this dynamic teaching methodology students will be able to critically review research articles in discipline and students will be able to develop and implement computer simulations. 


\section{CONCLUSION}

In order to convert Ayurveda to global level from the traditional way, it is necessary to adopt the latest technological tools and scientific framework in Ayurveda education without deviating it from its fundamental principles .There is urgent need to change mindset of all stake holders including policy makers, teachers, Practitioners, students and manufacturers so that they realize the necessity of modernization with adoption of new technologies in Ayurveda sectors. Through quality education only we can improve the clinical and academic output, which in turn make them able to be presentable for ayurvedic principles. Today is the era of wisdom and knowledge-based industry therefore if modernization of Ayurveda education is adopted fundamentally it will flourish at global level.

\section{REFERENCES}

1. Patwardhan, Kishor and Patwardhan, Bhushan, Ayurveda education reforms in India Journal of Ayurveda and Integrative Medicine doi = $\{10.1016 /$ j.jaim.2017.05.001\}

2. Vyas, Mahesh, Reforms in Ayurveda education; the challenges ahead Ayu 10.4103/0974-8520.182759 2015/07/01

\section{Source of Support: Nil}

\section{Conflict of Interest: None Declared}

How to cite this URL: Nitesh Gupta \& Rashmi Tiwari: Transformation Needs in Ayurveda Education: Where \& How. International Ayurvedic Medical Journal \{online\} 2020 \{cited October, 2020 2 Available from: http://www.iamj.in/posts/images/upload/4761_4765.pdf 